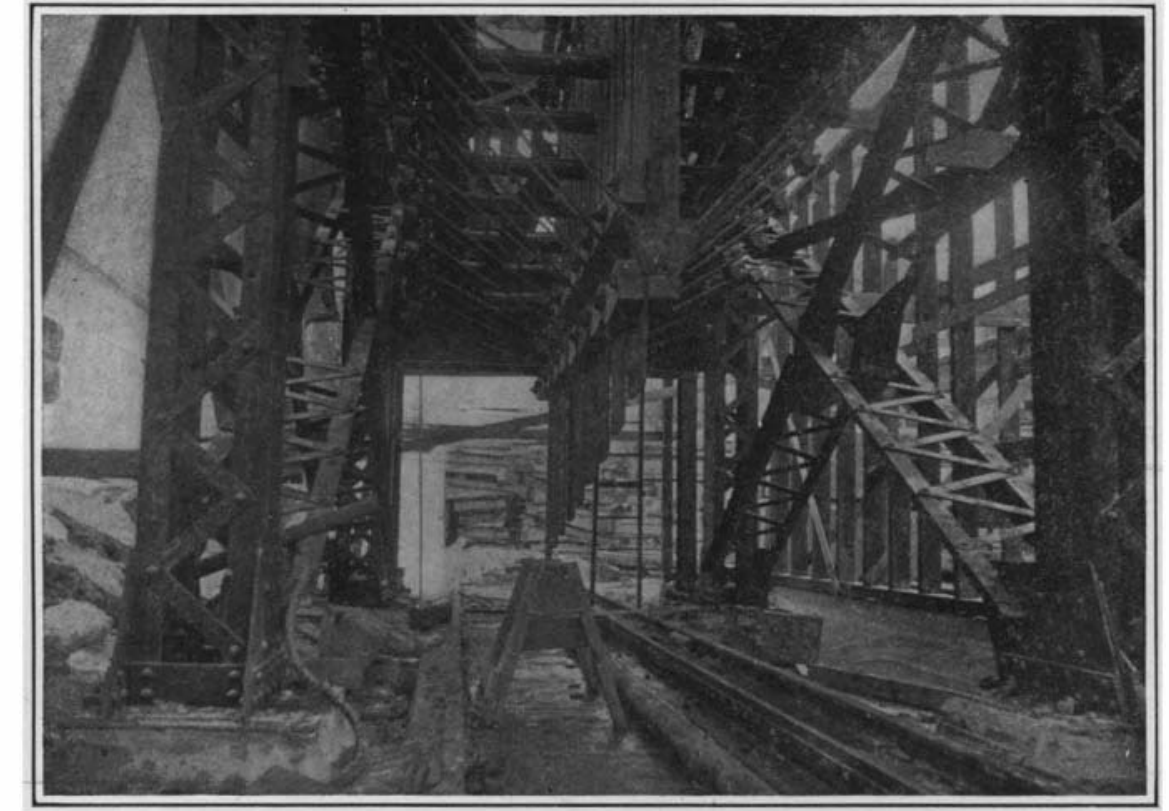

Fig. 1.-Battery of Granite Saw Blades in Position.

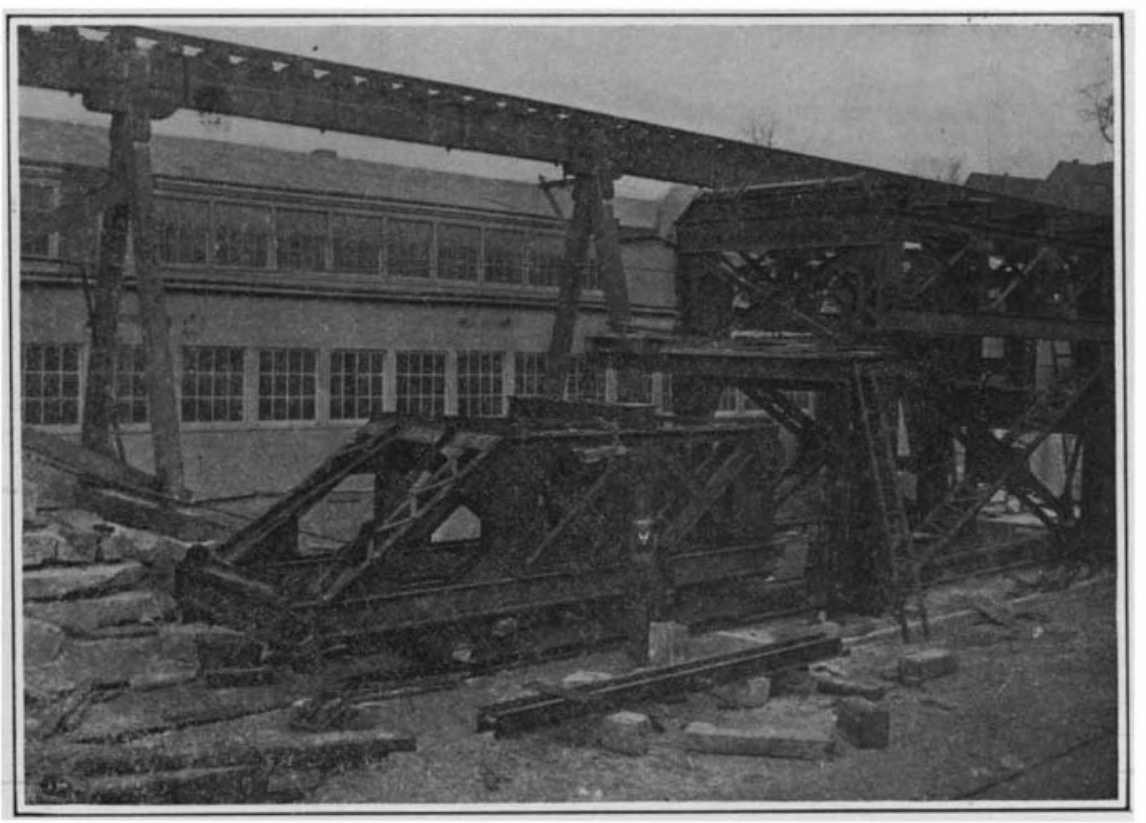

Fig. 2.-The Inner and Outer Frame Work of the Granite Saw.

\title{
A Machine for Sawing Granite
}

\section{A Most Useful Adjunct in the New England Quarries}

\author{
By Frank C. Perkins
}

Amono the large and numerous granite quarries of New England, where the operation of quarrying and cutting of some of the hardest known granites has become one of her leading industries, a most interesting machine is used for sawing and saving the granite. The accompanying illustrations, Figs. 1 to 4 , show the details of construction of this device, while Figs. 5 and 6 indicate the work that it accomplishes.

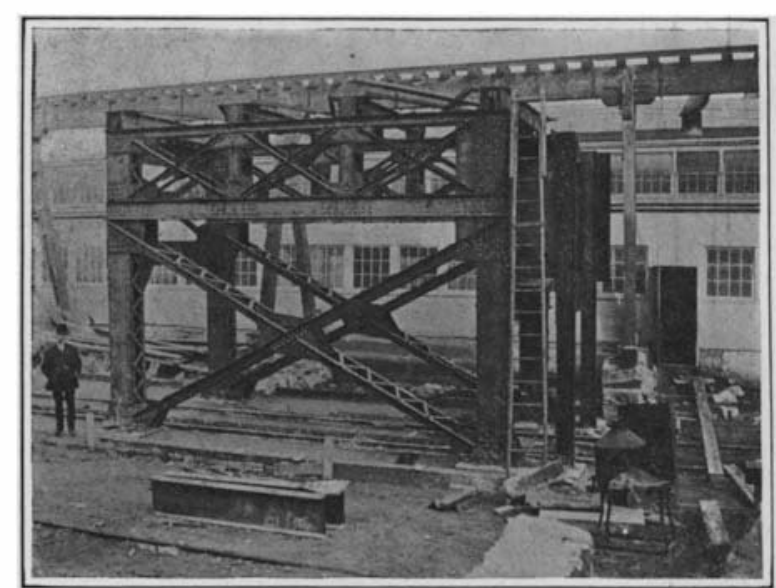

Fig. 3.-The Outer Framework.

The advent of the machine in these eastern localities has proven of great value to the granite trade in turning out surfaces so smooth and straight that the cost of bushing a sawed surface to a finish is reduced to less than four cents per square foot. At the same time the waste stone is diminished to the smallest amount possible, the machine producing many times more square feet of surface per day than has ever been done heretofore.
The advantages $\bullet$ btained by the use of this machine are many. Among these is the ability to saw any length of stone, such as spire and roof stones for vaults Owing to the construction of the cars and their clamping devices, small stones can be sawed as well as large ones at no great additional cost, thus making it very practical for use in many quarries where large'sa w blocks are not obtainable.

In building work there is usually one side of the material exposed, but by the use of the monocut of this saw there is no sawed surface or stone wasted, as the blocks are quarried large enough to make two stones by sawing through the middle. This method puts a surface on each stone for exposure and with no waste sawing, as is the custom with gang saws which make four or more cuts in large blocks and which produce slabs with two sawed surfaces, where with others only one finished surface is necessary.

The saw is constructed of structural steel, the length of the outside frame being from 23 to 33 feet and the width 11 to 18 feet, while the height measures 18 feet. The outside frame is made of very heavy steel and of very rigid weights ranging from 25 to 30 tons. This frame is set on concrete foundations and securely bolted thereto. The inside frame is also of structural stee and weighs from 8 to 12 tons. This is hinged or pivoted to the rear columns of the outside frame and the height of either end can be varied at will to accommodate the depth of stone going through the saw. The operation of raising and lowering either end of the inside frame and therewith the blades is done simultaneously with the cutting without stopping the mahine. Br the universal adjustment of this frame the greatest uniormity of cutting can be maintained and approximately the same amount of square feet of sawed surface an be produced per hour whether operating in stone measuring 2 feet or 5 feet. The head shafts, heads and cutting blades with their adjustment rods are suspended from the under side of the inside frame. Each head is pivoted on its individual cross shaft, held in heurnals. It carries at its lower extremity a steel cuting blade, and the cutting ends of the blades oscillate hrough an arc of approximately 2 feet 3 inches. These heads and blades are so proportioned that they cut a series of intersecting arcs, each blade cutting its own separate arc and each arc lapping into those of the nex

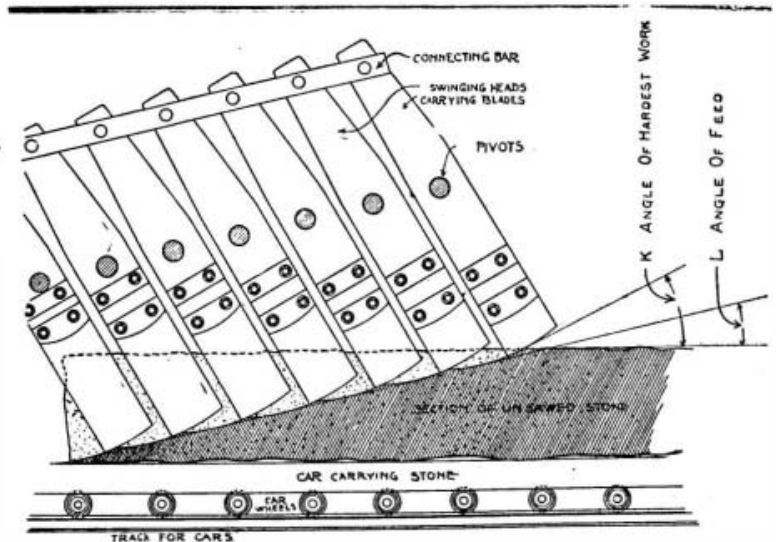

F'ig. 4.-The Saw Blades and Their Pivots.

adjacent blade both fore and aft. The front or shortest blade cuts a channel straight along the top of the stone, and the remaining blades follow in this chan nel, each cutting its proportionate amount deeper until the last blade cuts completely through the stone.

This arrangement breaks up the straight line cut on the edge of a long, thin blade, held at its ends and forces the abrasive material to pass down by the sides of the blades before coming to its cutting po sition (as in gang saws) into a series of circular cut

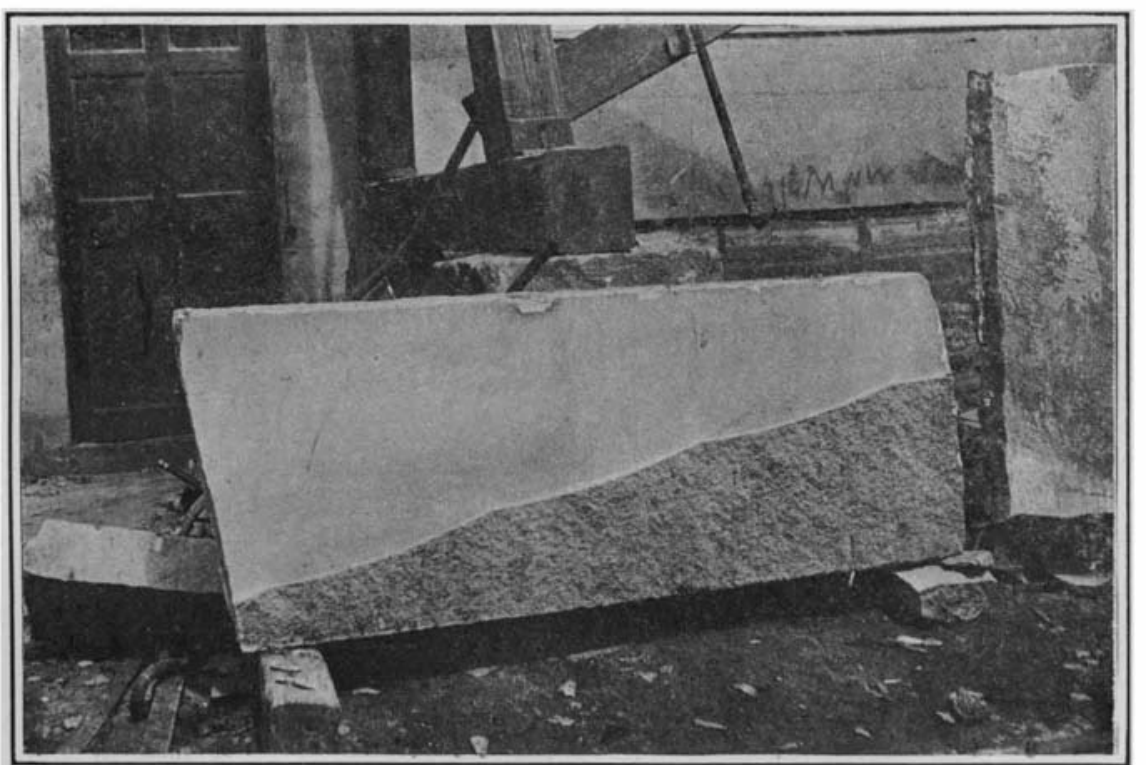

Fig. 5.-Granite Block Broken in Two After Having Been Partially Sawed Through.

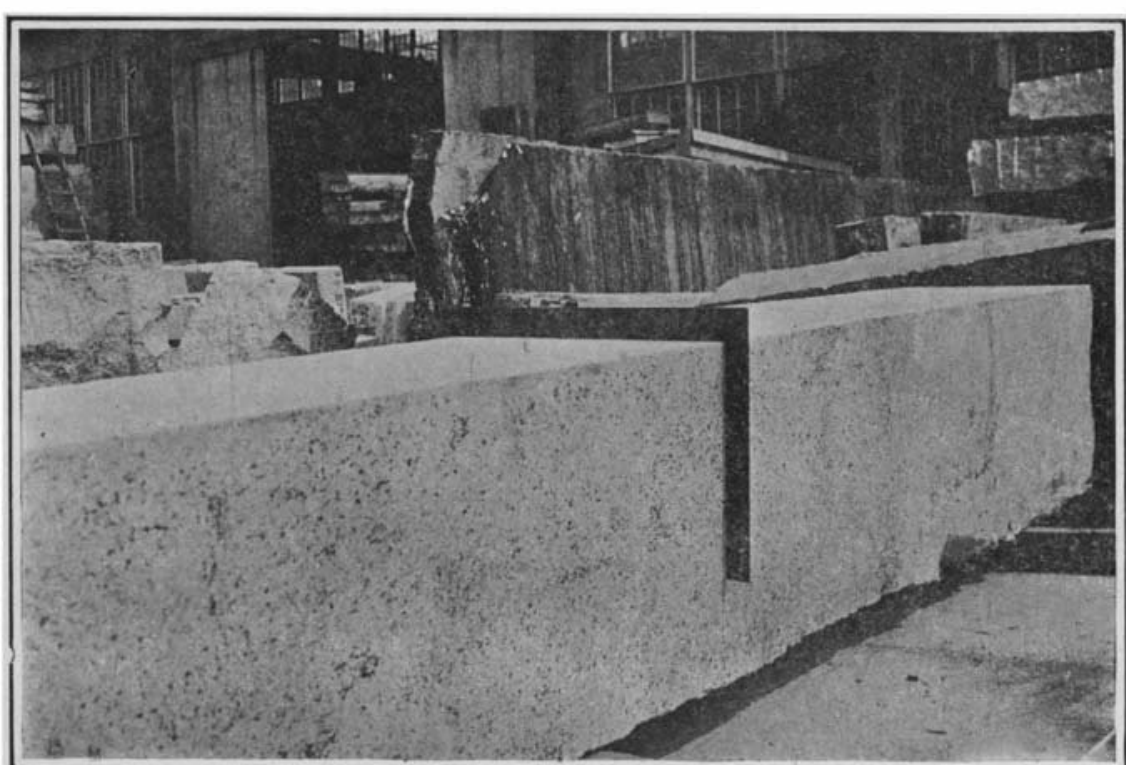

Fig. 6.-A Long Granite Beam With Two Faces Finished by the Saw. 
on the ends or points of the several individual blades where the abrasive material advances from one cut to the next, and is thus fed automatically at each stroke, directly under the cutting ends of the blades without passing by the sides.

It will be noticed that the heads, carrying each an individual cutting blade, are all united by a parallel bar connecting rod at the top and that they swing simultaneously through their several arcs. The connecting rod is driven from a crank on the main shaft by a pitman arm connection. The cutting is accomplished by the use of chilled steel shot under the cutting blades.

The shot, with sufficient water, is fed into the cut around the first leading blades and follows from arc to arc and blade to blade down the incline during the swing of the blades through the stone, the shot and muck finally passing out of the cut and away from the stone at the rear end, and after the shot has served its purpose of cutting under each and every blade in turn. The process of cutting is, therefore, a crushing one produced by the rolling of the steel shot into the stone under the ends of the blades. The shot at the same time serves as a roller bearing or lubricant to facilitate the rapid and free movement of the blades against the stone. The blades are lowered to compensate for the wear, and when worn too short for further use in their several original positions are moved forward, each blade thus serving in each position consecutively from the rear, where they are 7 feet 6 inches long, to the front, at a length of only 2 feet 6 inches.

This machine in principle is practically an oscillat ing drill, where the cutting power is applied directly to the point of the cutting tool or the blade, in a straight line between the point of application (pivoted head shaft) and the point of resistance (the stone bein cut) and similar in directness to the hammer and chisel in the hands of the stone cutter. This principle of application of power differs essentially from that of the gang saw where the cutting force is applied to the ends of long blades and through them, by their longitudinal edges, to the stone, thus passing the force through two right angles before reaching the surfare to be cut instead of applying it direct.
On account of this improved application of nower the saw produces an average of 10 surface feet pe horse-power per day, where the usual practice under former methods rendered not more than 2 surface feet. The saw blocks of stone are quarried as large as possible and loaded upon cars 15 feet long by 4 feet 8 inches wide, each supported on twelve chilled cast iron tricks or wheels which run on a track aligned longitudinall with the blades. These cars are guided in their passage through the saw by head guides and shoes arplied t the ball of the rail and assures the absolutely stroight cut into and through the stone. The loaded cars ar drawn through the machine by a screw 25 feet long. 4 inches in diameter, and 1 inch pitch placed between the rails operated by a variable speed drive ard chain of gears, and can be passed by the blades at coustant speeds varying from $1 / 2$ inch to 5 inches per minute, according to the height and hardness of the stone bein sawn. As each individual blade has its proportion cutting to do, it follows that a 9-blade saw going through stone 2 feet high, each blade would cut a kerf of $2 \% /$ inch depth only, while in stone 4 feet thick or high each blade would cut a channel $51 / 3$ inches deep. A stone 2 feet high passing the saw at 4 inches per minute would be cut at the rate of 40 square feet of cut or 80 square feet of cut surface per hour, while stone 4 feet high of the same grade would pass the saw at 2 inches per minute and the resulting amount of cut stone would remain the same. This saw will operate on any length of stone that can be quarried, the car being so dove-tailed that the joints between the stone need not coincide with those of the cars, and a stone may extend over one, two or three cars if desired, th lengths of the piece being limited only by the capacity of the quarry.

When a stone and its supporting cars have passe the saw the car is unloaded, raised from the track by the attending derrick or crane and returned to the front of the machine, to be again reloaded with ston operation of feeding the stone to the saw is continuous and the machine may be run constantly throughout the 24 hours, stopping only about every one hundredth hour to replace worn blades. The fioor of the space occupied by the machine is concreted and channeled
to facilitate the collection of the shot and the drainage of the muck.

The length of stone to be sawed is limited only by the capacity of the quarry to produce long stone. It is first loaded on cars and advanced forward to the blades by means of a screw (35 feet long) which is constantly pulling the car through the machine, thus enabling the saw to make a continuous operation. All that is necessary is to keep the stone loaded on cars in front of the saw; then as the car emerges from the back end of the saw the stone is cut in two, and the car unloaded, replaced in front of the saw and reloaded. The fact that all cuts are on a slight incline is a great advantage over the gang due to the fact that during the operation of sawing the saw is constantly washing the mud out of the cut and keeping each blade well supplied with shot. Each blade cuts an independent surface of its own, and on account of the difference in the wear of each piece of steel, one piece may wear off faster than the other. When this occurs, the next following blade has a trifle more cutting than the adjoining blades, and it is unnecessary to stop to adjust the blades. With the arrangement of the blades it will be observed that as the blade becomes too short from wear to cut through the stone it is taken out, the other blades moved up, one head and a new rear blade put in, making the last blade eventually the first.

Regarding the construction of heads and blades, it is found that the principal reason for this special construction and arrangement of the blades cutting an arc is to break up the cut of the gang saw which was a straight line cut, and in order to overcome the old method this saw is arranged with heads and blades in alignment so that one is longer than the other, from the front to the rear, and pivoted at their central points so that all swing simultaneously as shown in the diagram, making one cut on an incline. By this method of operation the cut is made up of intersecting arcs as there presented, where $K$ is the angle of hardest work for these blades and $L$ is the angle line of feed.

\section{The Irrationality of War}

\section{Science as an Element in the Developing of International Good Will and Understanding}

\section{By Sir Oliver Lodge, F.R.S., O.M.}

Humanity is a race of workers, and on its output of energy the well being of the planet now largely depends. The work of the human race is directed toward

(1) Sustenance,

(2) Advancement

and on the whole the work is conducted at high pressure and there is little margin to spare. The more energy that has to be expended on mere existence the less is available for progress and development. Consequently it is in moderately fertile countries an peaceful times that the greatest steps in Art and Science have been made. When existence is threatened there is neither time nor opportunity for advance.

Humanity works in sections, and it is possible for these sections to quarrel and to seek to injure or destroy each other; thereby interfering with each other's bare subsistence, and taking attention off higher thing It is notorious that in such disputes much energy can be unprofitably consumed, or, more accurately, degraded; and also that even if there is no active quarre between two sections, still the possibility of it entails severe preparation and anxiety and much unprofitable caution and disabling fear. So it used to be at on time between families, then between tribes, and now between nations; yet the sub-division of the Race into nations, with differing facilties and a variety of customs and traditions, ought to have a beneficient influence as well as add greatly to the interest of life. So long as the sections co-operate and mutually help each other, all is well: each benefits by the discoveries and advances of the rest, and a valuable spirit of Emulation is aroused. But when emulation degenerates from wholesome rivalry into a spirit of envy, hatred, malice and all uncharitableness, so that the sections wage an internecine confiict, then the warring among the members is a calamitous evil, and humanity as a whole is bound to suffer.

$$
\text { SCIENCE A COSMOPOLITAN ENTERPRISE. }
$$

In some departments of civilized life the risk of unwholesome and mutually destructive contest is more rife than in others. Certain fields of labor there are in which the spirit of rivalry never now degenerates int * Copyright 1912 by the $\Delta$ merican Association for Interna tional conciliation. hostility and mistrust. These are the cosmopolitan en terprises and labor to which every nation can contribute, and in the results of which every nation can share. Of all these cosmopolitan efforts those included under the general head Science are among the chief. Literature is more of a National product, the literature of one nation necessarily apueals less forcibly to another nation; alien language is a bar to complete enjoyment. But scientific discovery can be made at once in teresting, can be assimilated and its fruits reaped by all. Any discovery made by a group or by an individual becomes thereafter the property of humanity, and the world is advanced a step higher. And, short of catastrophe, such a discovery is made forever; it is not liable to decay like a picture or a statue; it is in the spirit, so to speak, it is not incarnate. Many discoveries are not only world wide but cosmic, and if ever we are able to communicate with another planet they could be appreciated there too. This is especially the case in such subjects as Mathematics, Physics, and Chemistry, and is probably true of a great part of Biology also. These great fundamental sciences are cosmic in their scope and significance. These and all other sciences are at least international. Science tends to weld the nations together; and even though petty jealousies and personal rivalries exist for a time, they seldom survive a generation; they are felt to be unworthy and unseemly, and the successful worker sooner or later meets with a world-wide appreciation.

The Labor and Problems of Peace Times.

But it needs all the energy, all the spirit, all the encouragement that can be given, to pursue this work; the labor of peace times is indeed strenuous, the problems to be solved demand the keenest intelligence, the most indomitable patience; and they represent a strain on the highest powers of a nation. To produce a Helmholtz or a Kelvin is a demand on national vigor-a feeble nation cannot as a rule produce great men. Appreciation also is necessary, and appreciation from other nations is especially welcome and is usually forthcoming; it is a sign and token of civilization when such is the case; and the fact of appreciation reacts with especial benefit and stimulus on the otherwise solitary worker. For such a man must be in ad wise solitary worker. For such a man must be in ad-
vance of his contemporaries, and yet must not be too hopelessly and utterly beyond the appreciation of them all; the career of a great genius becomes well nigh impossible when the general standard is low. To cultivate science therefore demands high qualities and strong character; it is a task of difficulty; whereas to rush into a quarrel and fight is easy enough. A savage in this art is an adept. No demand is made on selfcontrol, no lofty national spirit is needed in order to fall into a misunderstanding or to feel the pangs of envy and of greed. And yet it is in the encouragement of this facile mood that the greatest national enthusiasm and Patriotism are felt, merely because the condition recurs at intervals, like an appetite; whereas the stead $r$ strain of work for the common good excites no enthusiasm, calls forth no encouragement, and but little recognition or praise. Smooth indeed is the path to a quarrel, easy is the descent to war, night and day the gates stand open; but to take up again the works of peace, to climb the step ascent of Science, that is the burden, that the toil.

ANCIENT AND MODERN WARFARE.

Nevertheless it is often claimed that high qualities are demanded by modern warfare; and the claim is well founded. Qualities of mind and body are indeed evoked by it, and the nobler the nature the more can it respond to the demand, when the special call comes. That is what is asserted, and that is surely true; but this is only one aspect of the universal struggle for existence, it is a natural result of all corporate effor towards a common end: such qualities should be called out by every kind of emulation between nations; and would be, if only the pressure were occasional and episodical instead of constant and steady. Use and wont seem to blunt the feelings, and sap the energy of the average man. But it is not a different set of qualities that are needed in war, it is the same qualities raised to incandescence by the momentary burst of national feeling. For how are high faculties stimulated by war? Not by the mere killing-the killing is an episode, almost an accident; the actual fighting is a small part of a campaign. The rage to kill may have a survival value, but it is rapidly becoming obsolete: there is no real lust of slaughter in modern warfare it is regarded as a grim inevitable necessity. Modern fighting is mostly done by machinery-especially naval 